\title{
A DINÂMICA ESPACIAL DA PAISAGEM DE CHAPECÓ (SC): INTERPRETAÇÃO DO PROCESSO DE CONSTITUIÇÃO DO MOSAICO ANTROPIZADO
}

\author{
SPACIAL DYNAMICS OF CHAPECÓ (SC) LANDSCAPE: \\ THE CONSTITUTION PROCESS INTERPRETATION OF ANTHROPIZED MOSAIC
}

\author{
Ana Laura Vianna Villela \\ Daiane Regina Valentini \\ Alexandre Mauricio Matiello \\ Tomé Coletti \\ Vera Regina Tângari
}

\section{RESUMO}

Este artigo aborda a estruturação, transformação e dinâmica da paisagem na Sub-Bacia do Lajeado São José, no município de Chapecó, estado de Santa Catarina - Brasil, a partir de revisão bibliográfica e o uso da ferramenta GIS para o mapeamento e a interpretação tipomorfológica dos processos que constituem essa estrutura. Como critério teórico, assume-se a interpretação ecológica da paisagem como um meio de compreender o território, considerando nesse processo suas problemáticas, conflitos e dinâmicas de estruturação do espaço, bem como as potencialidades de ordem social, econômica, cultural e ambiental. Nesse contexto, é revelado o mosaico antropizado das heterogeneidades/homogeneidades dos processos de constituição que possibilitam identificar e definir as unidades de paisagem, sendo essas um meio de estruturar o território e articular ações efetivas para o planejamento na escala da cidade/fragmento/sub-bacia. A partir dos dados levantados, demonstra-se como o pensamento ecológico fundamenta o necessário aprimoramento das políticas públicas - neste caso, ao propor o redesenho dos macrozoneamentos à luz da dinâmica espacial da paisagem de Chapecó - e, assim, se apresentando como uma alternativa viável para o macroplanejamento dos municípios.

Palavras-chave: Unidades de Paisagem. Macrozoneamento. Sub-Bacia do Lajeado São José. Chapecó-SC.

\section{ABSTRACT}

The article discusses the study of the structure, transformation and dynamics of the landscape in the Sub-basin of Lajeado São José, city of Chapecó, state of Santa Catarina -Brazil from a bibliographic review and the use of the GIS tool for the mapping and morphological interpretation of the processes that constitute this morphological structure. As a theoretical criterion, the ecological interpretation of the landscape is interpreted as a means of understanding the territory, considering in this process its problems, conflicts and dynamics of space structuring, as well as the potential of social, economic, cultural and environmental order. In this respect, is revealed the anthropic mosaic of the heterogeneities/homogeneities of the constitution processes that allow the identification and definition of the Landscape Units (UP), being a means of structuring the territory, as well as of articulating effective actions for planning in the scale of the city/fragment/subbasin. From the data collected, it is verified how the ecological thinking supports the necessary improvement of public policies - in this case, when it is proposed to redesign the macro-zoning in light of the landscape spatial dynamics of Chapecó - and thus presenting itself as a viable alternative for the Macroplanning of counties.

Keywords: Landscape Units. Macro-Zoning. Sub-basin of Lajeado São José. Chapecó-SC. 


\section{INTRODUCTION}

O processo de urbanização brasileira está longe de ser um tema de simples explicação e compreensão. A partir do século XX, temse a efetiva consolidação das fronteiras, a ocupação do território nacional e a consolidação da inversão populacional do campo para a cidade, desenvolvendo cidades em um "modelo geográfico de crescimento espraiado, com um tamanho desmensurado que é a causa da especulação" (SANTOS, 1994, p. 9). O urbano se complexifica em fluxos de informação e de matéria, pela industrialização e pelo grande crescimento econômico nas cidades médias $^{1}$, principalmente nas de regiões agrícolas e agroindustriais ativas. Nesse contexto, o desenvolvimento urbano e regional vem conquistando cada vez mais espaço nos estudos e discussões, visto a crescente necessidade de elaboração de políticas, planos e diretrizes, que tradicionalmente se originam em políticas públicas que procuram uma normatização geral acerca de instrumentos de planejamento e gestão urbana. No reverso dessa postura está o estudo da paisagem como elemento-chave para compreender e elaborar novos rumos para o ordenamento do território, pois se estrutura a partir do reconhecimento e interpretação das diversidades e dos distintos aspectos sociais da realidade humana.

Com esse aporte da realidade, o trabalho procura compreender a dinâmica da paisagem dos municípios que a partir da década de 1950 , e principalmente a partir de 1970 , se engajam no processo de consolidação das fronteiras nacionais e de descentralização da força produtiva das metrópoles para o interior do país, alterando a matriz econômica local no intuito de atender não somente ao mercado interno, mas também à exportação (SANTOS, 1994): no caso do oeste de Santa Catarina, com a implantação das agroindústrias.

Os impactos dessas políticas norteiam novos rumos para a urbanização e o desenvolvimento regional, como no oeste catarinense, à luz das características do processo nacional e das decisões socioeconômicas. A globalização e as tecnologias de comunicação e informação têm influenciado e impactado diretamente cidades como Chapecó, que se destacam na centralização regional

1 Para maior compreensão do termo cidade média ver: Silva e Sposito (2017). de produção, consumo e circulação de mercadorias e pessoas, expressando em sua forma a força de trabalho, as atividades comerciais e de serviços, o capital, o poder político e econômico (SPOSITO, 2007).

Com um processo particularizado de desenvolvimento e crescimento, as chamadas cidades médias/não metropolitanas ganham expressão a partir das décadas de 1960 e 1970, pois até então o Brasil era considerado um país agrário. Segundo Sposito $(2007$, p. 9) cidades médias, são as que "estabelecem intermediação entre cidades maiores e menores no âmbito de diferentes redes urbanas e que, portanto, diferem das denominadas 'cidades de porte médio' cujo reconhecimento advém de seus tamanhos demográficos". Para Corrêa (2006), a compreensão desses territórios perpassa pela combinação articulada entre tamanho demográfico, funções urbanas e a organização do espaço urbanizado.

A partir dos anos de 1980, e mais intensamente na década de 1990, observa-se que as cidades consideradas pequenas e médias passam a assumir um significativo crescimento populacional e, sobretudo, um crescimento de atividades econômicas que antes eram encontradas apenas nas metrópoles (SPOSITO, 2007). Esse processo acaba por desenvolver uma nova urbanização em todo o território nacional, influenciando a paisagem de diferentes regiões até então rurais. A compreensão dessa realidade socioespacial exige conhecimentos específicos sobre as dinâmicas territoriais, assim como dos agentes que influenciam as transformações locais e regionais.

Na pauta de questões para compreender o processo de urbanização no Brasil, Santos (2006, p. 209) expõe relevante enfoque: o espaço materializa o tempo, ou seja, registra as intenções pensadas e executadas para cada cidade e avança ao entender que "a paisagem urbana reúne e associa pedaços de tempo materializados de forma diversa e, desse modo, autoriza comportamentos econômicos e sociais diversos", o que se, por um lado, torna mais complexa a análise, por outro, permite a reflexão sobre seus múltiplos aspectos. Macedo $(1999$, p. 11) compreende a paisagem enquanto articuladora dos processos citados, pois ela: 
pode ser considerada como um produto e como um sistema. Como um produto porque resulta de um processo social de ocupação e de gestão de determinado território. Como um sistema, na medida em que a partir de qualquer ação sobre ela impressa, com certeza haverá reação correspondente, que equivale ao surgimento de uma alteração morfológica parcial ou total.

Dessa forma, a paisagem se coloca como corolário das interações entre os elementos naturais e antrópicos, organizados de maneira dinâmica num dado espaço geográfico e período de tempo que, segundo Santos (1997), representa diferentes momentos do desenvolvimento de uma sociedade. Neste sentido, e à luz do sistema de categorização e análise da paisagem utilizada pelo grupo de pesquisa Sistemas de Espaços Livres - Rio de Janeiro (SEL-RJ) da Universidade Federal do Rio de Janeiro (UFRJ) e pelo Laboratório do Quadro do Paisagismo no Brasil - Sistemas de Espaços Livres (Quapá-SEL) da Universidade de São Paulo (USP), serão estudadas neste artigo a estruturação, a transformação e a dinâmica da paisagem na Sub-Bacia² do Lajeado São José, município de Chapecó-SC, a partir do mapeamento dos processos que constituem essa estrutura morfológica, reforçando o entendimento da paisagem como:

produto que incorpora os processos biofísicos e os processos sociais nela refletidos, em diversos tempos e escalas, e que apresenta elementos de integração ou fragmentação territorial, criando e recriando formas, funções e fluxos, com funções ecológicas diversas, em estágios diferentes de intervenção humana (SCHLEE et al., 2009, p. 235).

Analisar a paisagem é uma forma de compreender o território, e a análise tipo-morfológica é uma forma de contribuir para a reflexão dos métodos de avaliação que consideram os processos de construção social e de transformação das cidades/regiões.

2 Nomenclatura e delimitação definida no trabalho do Sistema de Informações Gerenciais tentável - Estado de Santa Catarina, ano de 2010.
Entende-se que, quando as problemáticas, os conflitos e as dinâmicas de estruturação do espaço, bem como as potencialidades de ordem social, econômica, cultural e ambiental são mapeadas e interpretadas, revelam o mosaico antropizado dos processos de constituição que possibilitam a identificação e definição das unidades de paisagem (UPs), sendo estas um meio de estruturar o território e articular ações efetivas para o planejamento.

Assim, a abordagem transdisciplinar aqui adotada abrangerá conceitos da Arquitetura e do Urbanismo, da Ecologia da Paisagem, da Geografia, da Psicologia e da Antropologia, vinculando-se tanto às relações biofísicas, de cunho material e objetivo, quanto às relações socioculturais e perceptivas, de cunho imaterial e subjetivo. Nesse contexto, as UPs devem ser estudadas a partir da interação desses dois campos de relações, e desses com a ação antrópica, que, em maior ou menor grau, registram as marcas e os impactos desta interação (BERTRAND, 1972; CONSELHO DA EUROPA, 2000; AB'SÁBER, 2003; SCHLEE et al., 2009).

\section{A CONTRIBUIÇÃO DO ESTUdO DA PAISAGEM PARA O PLANEJAMENTO URBANO}

A concepção de espaço possibilita refletir sobre a dinâmica da paisagem "em suas diversas escalas de análise, de apreensão e de intervenção, e as delimitações de territórios, posto que, esses, ao se definirem por seus significados socioculturais, também se referem diretamente a sistemas espaciais específicos" (SCHLEE et al., 2009, p. 242). Particularmente ressaltam-se as disputas pela terra, tanto urbana quanto rural, e as desigualdades da distribuição da renda que "levaram a conflitos e contradições que se refletem claramente na distribuição, na apropriação e no tratamento dos espaços livres e em sua relação com os espaços edificados" ( $\mathrm{SCH}$ LEE et al., 2009, p. 226).

Para Souza (1995, p. 78) o território é "fundamentalmente, um espaço definido e delimitado por e a partir de relações de poder". Claro que não é tão simples assim, pois, como bem lembra Arendt (1983, p. 212), o poder "só existe em sua efetivação" 
e complexidade. "Poder que, além de ambivalente, também é, conforme Castoriadis (e também Arendt) claramente sublinha, ubíquo" (SOUZA, 2015, p. 83). Essa onipresença necessita de uma sociedade "livre, autônoma" (SOUZA, 2015, p. 85) e não heterônoma que esteja "em igualdade efetiva de condições no processo decisório [...] definindo, inclusive, possíveis punições para os transgressores dessas regras, está exercendo poder, poder esse que se consubstancia sob a forma de um conjunto de normas" (SOUZA, 2015, p. 84). Parte deste conjunto de convenções pactuadas coletivamente - seja em forma de lei, decreto e/ou plano estabelece os processos de produção, estruturação e apropriação do território - elementos inerentes ao planejamento urbano e essenciais na leitura da paisagem.

Souza $(2000$, p. 79$)$ ressalta que o território se constrói e/ou desconstrói no exercício de poder, o que lhe confere as mais diferentes escalas de existência, tais como: temporal, quando permanente, por anos, por meses ou por dias de forma periódica, cíclica; e dimensional, podendo envolver espaços de diferentes dimensões, como vias e continentes, por exemplo. Nesse sentido, Souza (2000) ao compreender o território como o espaço de representação e aproximação de grupos sociais, define a territorialidade; e, ao entender que esse mesmo território pode ser ocupado por grupos sociais diferentes dependendo da temporalidade, como ao longo de um dia, por exemplo, define essa apropriação como territorialização. Ou seja, o território é uma das múltiplas faces do espaço social (SOUZA, 2015),

uma construção social, que incorpora os processos econômicos e produtivos, define estratégias de dominação sobre o espaço e seus recursos e que se manifesta sobre uma base física, através de múltiplas apropriações, individuais e coletivas, delimitando marcas e marcos de identidade cultural (SCHLEE et al., 2009, p. 231).

Dentre os estudos da paisagem, o da Ecologia da Paisagem tem uma abordagem que se pauta no estudo da estrutura, função e dinâmica de áreas heterogêneas compostas por ecossistemas interativos. A Ecologia da Paisagem se preocupa em entender as consequências do padrão espacial nos processos ecológicos. Ou seja: como a heterogeneidade se expressa espacialmente. Para tanto, estuda basicamente três características da paisagem: a estrutura, a função e as dinâmicas (FORMAN; GODRON, 1986; METZGER, 2001).

Forman e Godron (1986) compreendem a Ecologia da Paisagem como importante ferramenta para estudiosos, cidadãos e planejadores, pois essa teoria desempenha um papel único ao observar as heterogeneidades de uma paisagem. Com isso, percebe-se como os sistemas ecológicos estão entrelaçados: uma ação aqui e agora produz um efeito lá e depois - o sistema está interligado, sendo fundamental compreender as relações espaciais entre os elementos da paisagem, os fluxos, e a dinâmica ecológica do mosaico da paisagem. Essa compreensão está relacionada à influência dos padrões espaciais sobre processos ecológicos, bem como ao reconhecimento da influência da escala nos estudos ecológicos.

Na Ecologia de Paisagens, a compreensão da integração entre as partes de um todo e os diferentes níveis de ação dos elementos da paisagem - abordagem sistêmica - é muito utilizada. Em termos práticos, se propõe compreender as modificações que o homem faz no meio ambiente, procurando explicitar as alterações "estruturais e, portanto, funcionais, trazidas pelo homem no mosaico como um todo, incorporando de forma explícita toda a complexidade das inter-relações espaciais de seus componentes, tanto naturais quanto culturais" (METZGER, 2001, p. 7).

Para Wu (2012), estudar o padrão espacial sem relacioná-lo aos processos ecológicos é superficial, bem como seria incompleto investigar os processos ecológicos sem considerar os padrões espaciais. Assim, a Ecologia da Paisagem é a ciência da heterogeneidade e da escala, fornecendo um novo paradigma científico.

Nesse contexto, se insere a paisagem com sua essência física, material, objetiva e categorizável, bem como pela essência simbólica, experimental e processual. Ou seja: na profundidade cultural (LEITE, 1992; SCHLEE et al., 2009), sendo o grande desafio 
na contemporaneidade entendê-la na sua complexidade. Os atributos paisagísticos são compreendidos a partir da definição integradora de paisagem - "mosaico (antropizado) heterogêneo formado por unidades interativas, sendo essa heterogeneidade existente para pelo menos um fator, segundo um observador e numa determinada escala de observação" (METZGER, 2001, p. 1). Assim se trabalha com escalas espaciais e temporais amplas que utilizam ecossistemas, unidades de cobertura, ou uso e ocupação do território para representar as unidades de paisagem. O limite do conjunto interativo dessa paisagem se estrutura pelos fatores que, em um primeiro momento, condicionam a identificação de unidades de paisagem: ambiente abiótico, perturbações naturais e antrópicas (METZGER, 2001).

Contudo, as unidades de paisagem são os tipos de componentes da paisagem que constituem o mosaico de diferentes usos e coberturas sem ter as propriedades e dependências de um sistema, mas que condicionam e implicam no funcionamento da paisagem pela disposição e dependência espacial entre as unidades. Nesse contexto "a ecologia de paisagens pode ser assim entendida como uma ecologia de interações espaciais entre as unidades da paisagem" (METZGER, 2001, p. 5), se colocando como importante ferramenta para descrever e interpretar a paisagem a partir do estudo e compreensão das heterogeneidades/homogeneidades do território. Consequentemente, também são importantes para as reflexões que levam ao planejamento urbano, pois resultam da interação dinâmica de componentes os quais, na visão multiescalar, assumem importante papel para: escala da metrópole/regiões/ bacias hidrográficas - estrutura ecológica; escala da cidade/fragmentos/sub-bacia - estrutura morfológica (escala deste trabalho); escala do cotidiano/lugares/bairros - usos e apropriações.

\section{As UNIDADES DE PAISAGEM COMO FERRAMENTA PARA O PLANEJAMENTO DA PAISAGEM: O CASO De Chapecó}

O oeste catarinense tem um processo de estruturação dos municípios muito vinculado à ação dos agentes econômicos, princi- palmente da agroindústria, sobre os diferentes atores da região (VILLELA et al., 2015). O município de Chapecó-SC conta com uma população estimada de 213.279 habitantes (IBGE, 2017) e é entendido como cidade média/não metropolitana, uma vez que "participa cada vez mais do mercado mundializado no contexto da globalização, por intermédio do desenvolvimento de novas funções e diferentes atividades" (HASS; ALDANA; BADALOTTI, 2010 , p. 61), bem como pela contradição de, ao mesmo tempo, consolidar:

seu papel regional, influenciando territorialmente seu entorno em termos de produção, circulação e consumo, por outros, alcança escalas nacional e internacional, o que implica também sofrer os impactos que chegam a essas escalas. Entre a permanência e/ou mudança de agentes econômicos que reestruturam o urbano e o regional, a cidade também reflete esses movimentos, sobreposições e contradições (MATIELLO et al., 2016, p. 312).

A definição do recorte territorial deste trabalho pautou-se na Sub-Bacia do Lajeado São José, situada no oeste de Santa Catarina, abrangendo boa parte do município de Chapecó e que conta com uma área de 23.750,2ha (Figura 1). Esse aporte geográfico compõe a supra Sub-Bacia 73, uma das nove em que se divide a Bacia do Rio Uruguai, que abrange 384 municípios, tendo uma área de aproximadamente $384.000 \mathrm{~km}^{2}$, dos quais $174.494 \mathrm{~km}^{2}$ situam-se no Brasil, o que equivale a $2 \%$ do território brasileiro. Da área brasileira, $46.000 \mathrm{~km}^{2}$ estão no estado de Santa Catarina (AGÊNCIA NACIONAL DE ÁGUAS, 2010; BRASIL, 2006), correspondendo a $0,54 \%$ do território nacional.

De modo geral, quanto ao solo e relevo, tem-se a presença de mata nativa ainda relevante, e a fertilidade dos solos em seu estágio original bastante alta. Contudo, a política de colonização, combinada ao modelo de produção agrícola intensivo com uso de insumos químicos, levou ao esgotamento dos solos, tornando-os de baixa fertilidade. A região está situada em áreas de relevo suavemente ondulado a ondulado (WELTER, 2006; BRASIL, 2010). 


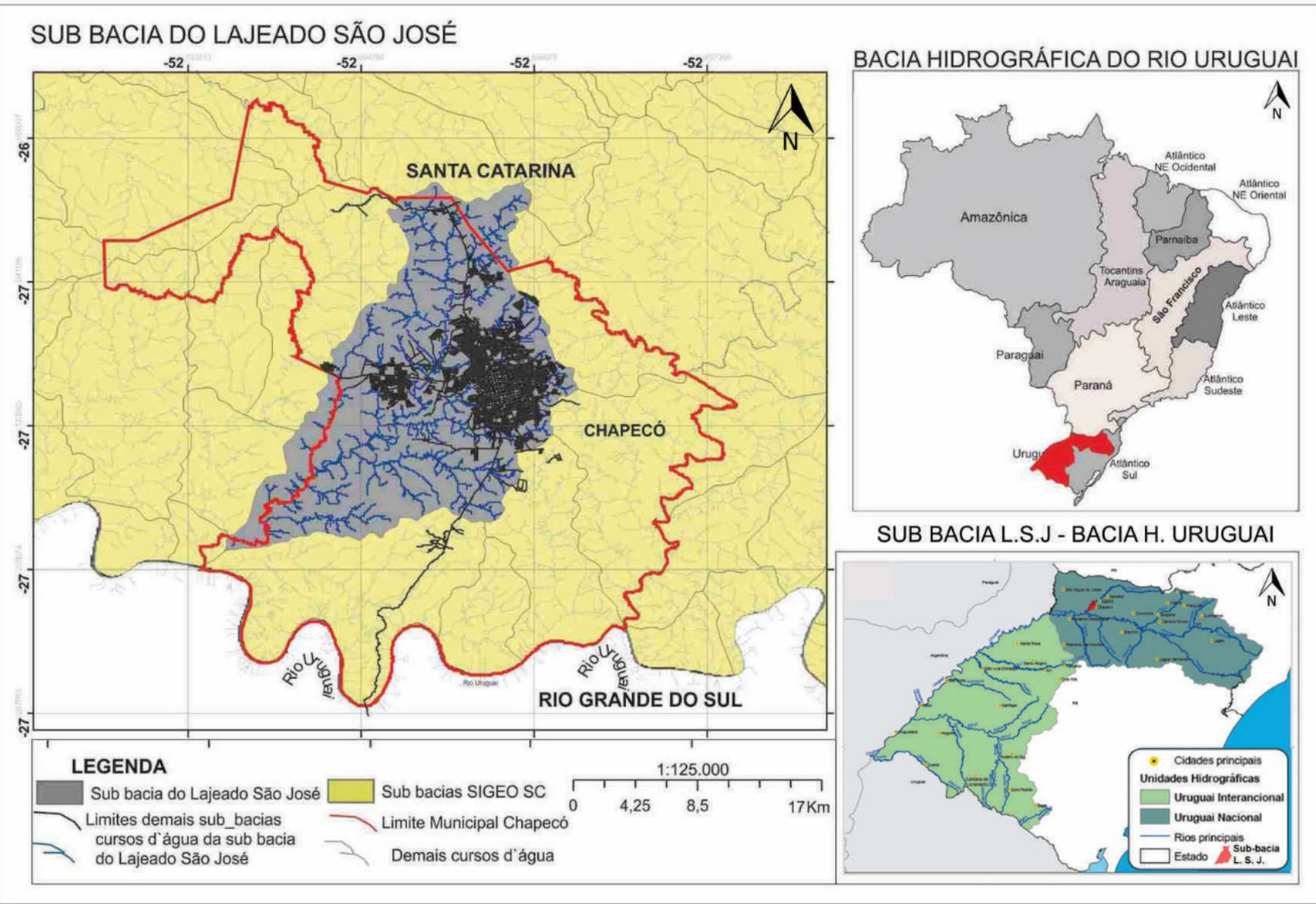

Figura 1 - Mapa de situação da área de estudo. Fonte: Base cartográfica estado de Santa Catarina; sistema viário de Chapecó. Elaboração e edição: Daiane Regina Valentini e Ana Laura Villela, 2018.

\section{As ANÁLISES DAS UNIDADES DE PAISAGEM}

Este estudo se propõe a analisar criticamente as diretrizes das políticas públicas implementadas no que tange às proposições para o sistema de espaços livres e seus rebatimentos sobre a paisagem a partir da compreensão das relações espaciais entre os elementos da paisagem, os fluxos e a dinâmica ecológica do mosaico da paisagem. Partiu-se da pesquisa teórica, documental e de levan- tamentos de campo realizada com base em Forman \& Godron (1986); Forman (1995, 2008); Tângari (1999, e 2014); Tângari et al. (2012) e no sistema de categorização e análise da paisagem utilizado pelo grupo de pesquisa SEL-RJ da UFRJ e pelo Laboratório Quapá-SEL da USP.

A metodologia aplicada teve como base o mapeamento e interpretação dos processos de constituição tipo-morfológica, tais 
como: (1) suporte físico - relevo, hidrografia, cobertura vegetal; (2) vetores de ocupação - atividades econômicas e fluxos, evolução da mancha urbana; (3) padrões de ocupação - tipos construtivos; e (4) planos, leis e agentes de transformação - marcos do processo de ocupação. Esses dados deram suporte à caracterização das unidades de paisagem (UPs), sendo os elementos mais relevantes para esse recorte em estudo as delimitações naturais ou artificiais, as delimitações históricas ou simbólicas, os padrões de ocupação e as características tipo-morfológicas/ambientais/funcionais.

Os mapeamentos foram desenvolvidos em ambiente de sistemas de informação geográfica (SIG) e geoprocessamento, com uso do software livre QGIS 2.18 e ArcGis 10.4.1, possibilitando capturar, armazenar e atualizar os dados, bem como exibi-los e analisar suas integrações.

\section{Constituição tipo morfológica da Sub- Bacia do Lajeado São José: Resultados e CRÍTICAS}

O mapeamento dos elementos tipo-morfológicos estudados na escala da Sub-Bacia do Lajeado São José possibilitaram sintetizar as características de seis UPs (Figura 2). Identificaram-se também os elementos mais significativos e representativos resultantes: das delimitações naturais ou artificiais; delimitações históricas ou simbólicas; dos padrões de ocupação; e das características morfológicas, ambientais e funcionais, além da contribuição destes para o planejamento urbano do município.

A partir do levantamento, do mapeamento cartográfico e da interpretação dos processos de constituição tipo-morfológica da sub-bacia quanto ao suporte biofísico, pode ser destacado que os elementos relevo, hidrografia e cobertura vegetal mostram-se significativos por meio das manchas de vegetação remanescente e de áreas de relevo acidentado, com destaque para o Vale do Rio Taquaruçú (rio principal da UP 3 - Figura 2).

O mapeamento realizado pela interpretação de imagens de satélites do mapa de uso do solo tem grande importância por demonstrar as áreas de reflorestamento, solo exposto, corpos d'água, pastagens e campos naturais, florestas em estágio médio, áreas urbanizadas e de agricultura, possibilitando a compreensão das áreas mais ou menos antropizadas, ou seja, das áreas com vegetação mais preservada, de produção e de intensificação da urbanização. De modo geral, os $23.750,2$ ha da área da sub-bacia se constituem em sete tipos de uso do solo (Gráfico 1 e Figura 3).

Para o mapeamento do suporte sociocultural, foram observados os vetores de ocupação, as atividades econômicas e os fluxos, tendo como referência estudos já realizados e levantamento em campo. Os vetores históricos de ocupação, referentes à mancha urbanizada consolidada, podem ser atribuídos, sobretudo a partir da década de 1960, à implantação das principais agroindústrias, que foram sendo incorporadas ao tecido urbanizado. Atualmente, além das agroindústrias, também se destacam como importantes atividades econômicas o ramo de indústria metal mecânica e moveleira, serviços de logística, ensino superior e saúde, além do mercado imobiliário (MATIELLO et al., 2016).

A análise dos suportes biofísico e parte do sociocultural (uso do solo) permitem caracterizar a mancha urbanizada como um maciço cuja forma espraia-se com um grande fragmento no sentido oeste e em fragmentos de menor intensidade para norte e sul (Figura 3). Quanto à hidrografia, os cursos d'água perpassam a área urbanizada de maneira a canalizar-se num sumidouro único na direção do Rio Taquaruçú a sudoeste da área de estudo (Rio principal da UP 3 - Figura 3). Quanto às áreas com agricultura, excetuando-se aquela a leste da área de estudo, onde a mancha urbanizada alcança grande expressão e impacto antrópico, percebe-se o uso para plantio e pastagens associado à remanescente de floresta e reflorestamento abrangendo boa parte dos contornos da mancha urbanizada.

Os acessos à rodovia BR 283 (sentido leste-oeste) e à BR 480 (sentido norte-sul) são importantes hubs regionais que impactam significativamente nos fluxos e circulação da área em estudo, por onde passam cargas e passageiros tanto de passagem como em busca dos polos de serviços da cidade. Caracterizam-se pela localização de empresas de logística e transporte, comércio ata- 


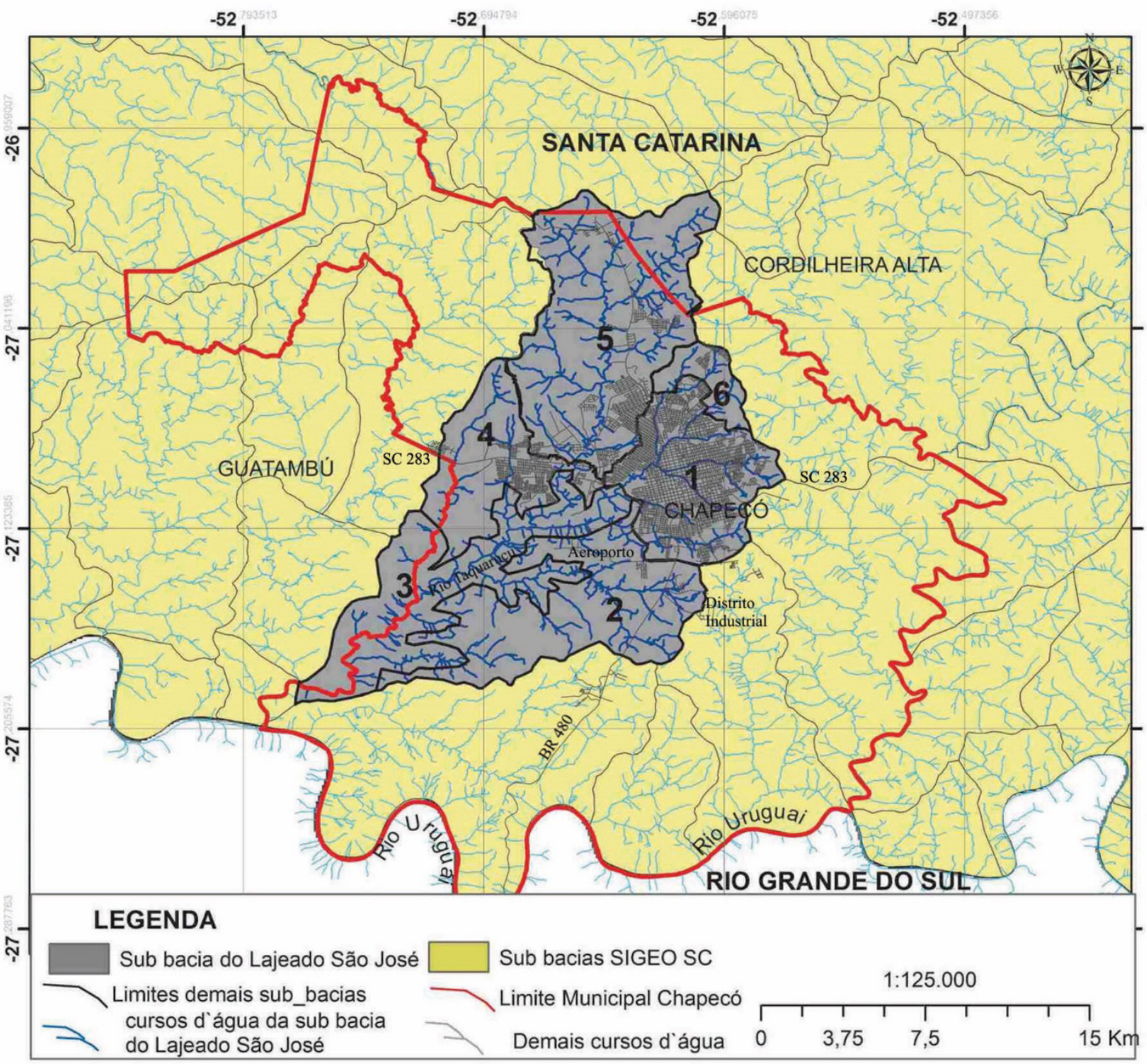

Figura 2 - Mapa das unidades de paisagem.

Fonte: Base cartográfica do estado de Santa Catarina; imagem de satélite de alta resolução disponível no ArcGIS

10.4.1 base Google Earth. Elaboração e edição: Daiane Regina Valentini, 2017. 


\section{Usos do solo da área da Sub-Bacia do Lajeado São José, Chapecó-SC}

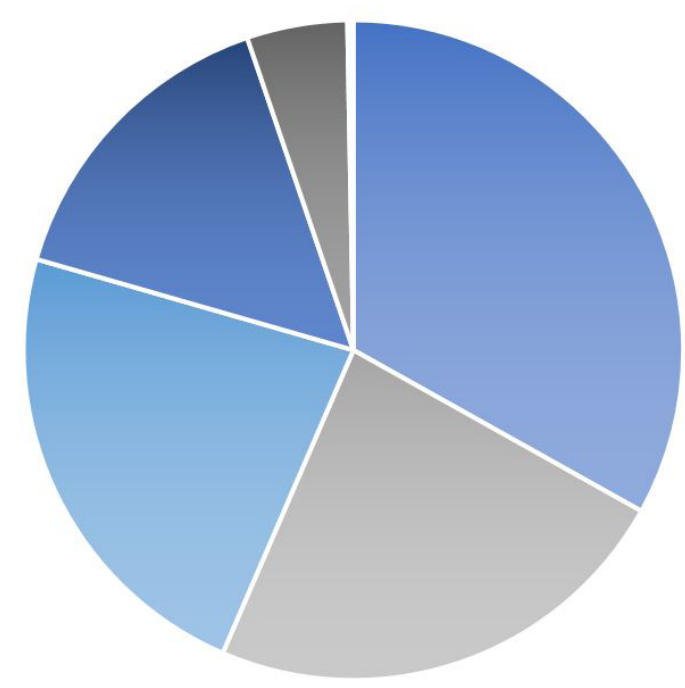

- Pastagens e campos naturais - 7.862,29 ha $(33,10 \%)$

- Florestas em estado médio - 5.551,52 ha $(23,37 \%)$

- Agricultura - 5.452,23 ha (22,95\%)

- Área urbanizada - 3.642,59 ha (15,33\%)

- Reflorestamento - 1.172,92 ha (4,93\%)

Gráfico 1 - Usos do solo da área da Sub-Bacia do Lajeado São José, Chapecó-SC.

- Corpos d'água - 52,13 ha (0,22\%)

Fonte: Levantamento do uso do solo Epagri/Ciram

- Solo exposto - 16,53 ha $(0,07 \%)$

cadista, indústrias alimentícias e químicas e, no caso da BR 480 (conexão com o Rio Grande do Sul), acesso ao Distrito Industrial. Destaca-se ainda o papel do aeroporto de desempenhar atração em escala regional pela articulação e mobilidade nacional-internacional. Nos últimos 15 anos também vêm sendo implantados alguns condomínios fechados em áreas rurais e descoladas da mancha urbana.

O estudo da evolução da mancha urbana (Figura 4) destacou os diferentes padrões de ocupação e tipos construtivos ao longo do processo de consolidação antrópica do território. De modo geral destaca-se, a partir dos primeiros assentamentos, a consolidação pela ocupação no Passo dos Índios - nome do núcleo original desenhado como tecido ortogonal, e que atualmente corresponde ao centro da cidade Chapecó (UP 1), no qual se observa nos últimos 10 anos um processo de verticalização mais intenso, superando os 30 pavimentos, em alguns casos.
A expansão a partir desse núcleo original ganha expressão a partir da década de 1970, devido à instalação mais intensiva das agroindústrias, na direção norte da malha urbanizada. A ocupação a oeste é intensificada a partir da década de 1990, sobretudo com a instalação de novas plantas industriais e da universidade federal. Mais recentemente, nos últimos 15 anos, a mancha urbana tem se espraiado sobre o solo outrora de produção primária, ou por vezes mesmo descolada da mancha urbana principal do município, como no caso de loteamentos fechados de média e alta renda e de conjuntos habitacionais populares.

O estudo dos planos, leis e agentes de transformação permite sinteticamente destacar as interferências históricas no processo de consolidação da área em estudo. Os planos diretores, em especial o da década de 1970 (CHAPECÓ, 1974), não conseguiram organizar a expansão urbana. Também foram responsáveis pela delimitação de áreas residenciais exclusivas, o que contribuiu 
MAPA SÍNTESE SUPORTE BIOFÍSICO E SOCIO-CULTURAL

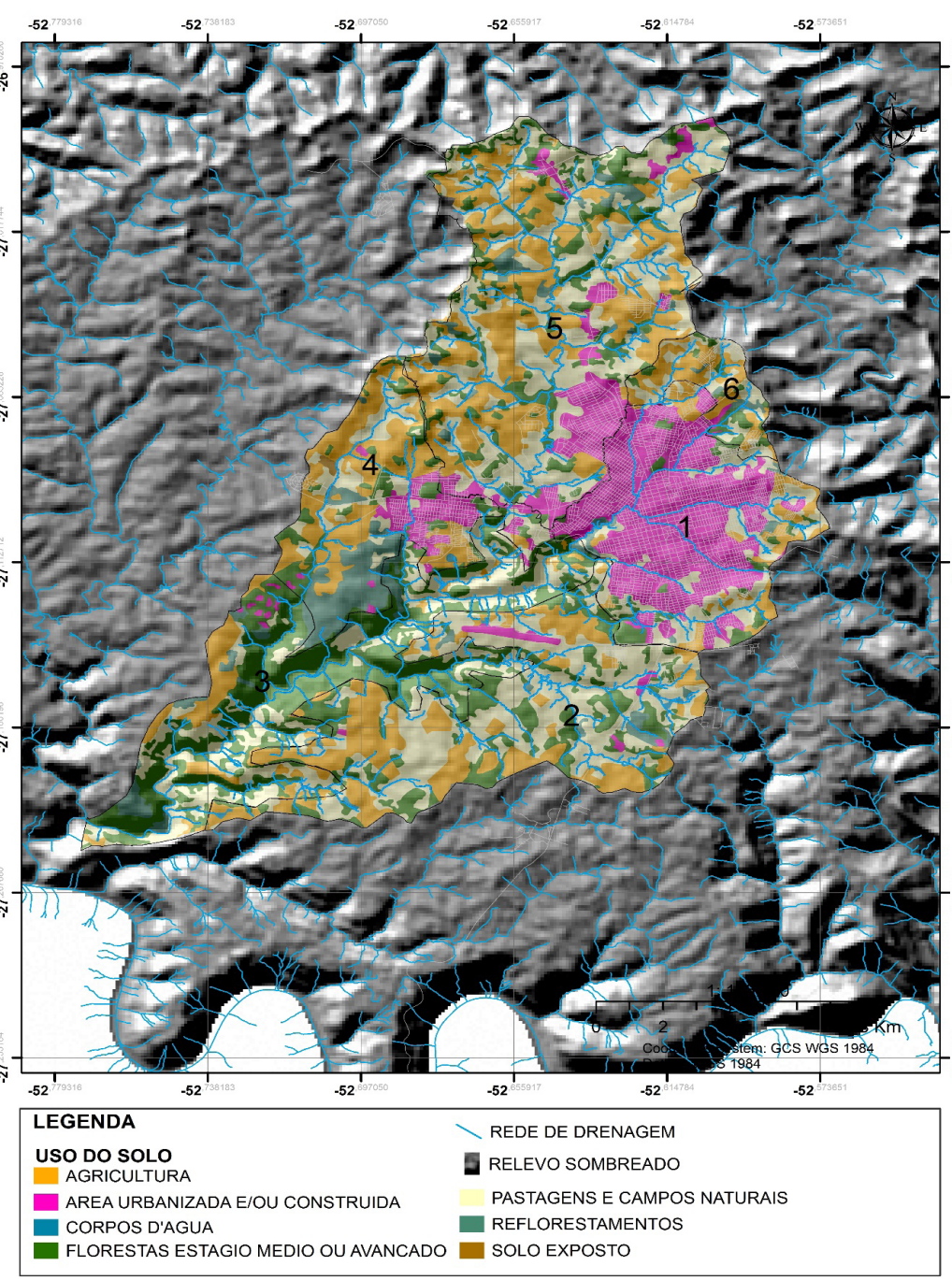

Figura 3 - Mapa síntese suporte biofísico e suporte sociocultural.

Fonte: Base cartográfica do estado de Santa Catarina; levantamento do uso do solo Epagri/Ciram; relevo sombreado do mapa hidrogeológico do estado de Santa Catarina. Elaboração e edição: Daiane Regina Valentini, 2017. para a segregação espacial. O plano da década de 1990 (CHAPECÓ, 1990) dificultou a instalação de habitação de interesse social em áreas com urbanização mais estruturada. Os anos 2000 foram marcados por um novo plano e suas revisões (CHAPECÓ, 2004; 2007; 2014), que deram margem à atuação intensificada do capital imobiliário. Nesse sentido, destacam-se o aumento dos potenciais construtivos, a multiplicidade de funções, o maior adensamento nas unidades funcionais de descentralização do desenvolvimento (UFDD) e a facilitação para aprovação de loteamentos em áreas de futura expansão urbana, acarretando a formação de novos vazios urbanos - sob concordância do Conselho de Desenvolvimento Urbano, hoje, ConCidades.

Também foi liberada, ainda que sob restrições, a urbanização sobre a área que corresponde à bacia de captação de água potável, principal fonte de abastecimento da área urbana (MATIELLO et al., 2016; RECHE, 2008; MONTEIRO, 2006). Esses fatores se somaram aos programas governamentais de apoio à habitação, como o programa Minha Casa, Minha Vida, e de infraestrutura urbana, com a reestruturação e instalação de eixos viários de conexão regional, ao longo dos quais têm se intensificado a ocupação do solo nas bordas da urbanização mais consolidada e, em menor escala, a ocupação de vazios urbanos.

Ao final, o mapeamento cartográfico dos elementos estudados possibilitou sintetizar a essência de cada uma das seis UPs identificadas, já demonstradas no Gráfico 1. Para tanto, se consideraram os elementos mais significativos e representativos que constam basicamente da compreensão das delimitações naturais ou artificiais e históricas ou simbólicas, dos padrões de ocupação e das características morfológicas, ambientais e funcionais.

A UP 1 (Figura 5) se destaca pela grande mancha urbana consolidada ao longo do processo de ocupação do território, pela densificação e processo de verticalização edilícia e pelo caráter habitacional e de atividades comerciais e de serviços (Figuras 6, 8 e 10). Representa $16 \%$ da área total em estudo, tendo pouca representatividade o uso de pastagens e campos naturais, agricultura e florestas em estágio médio. Apresenta relevo de solos suavemente ondulado e ondulado; declividade predominante de 


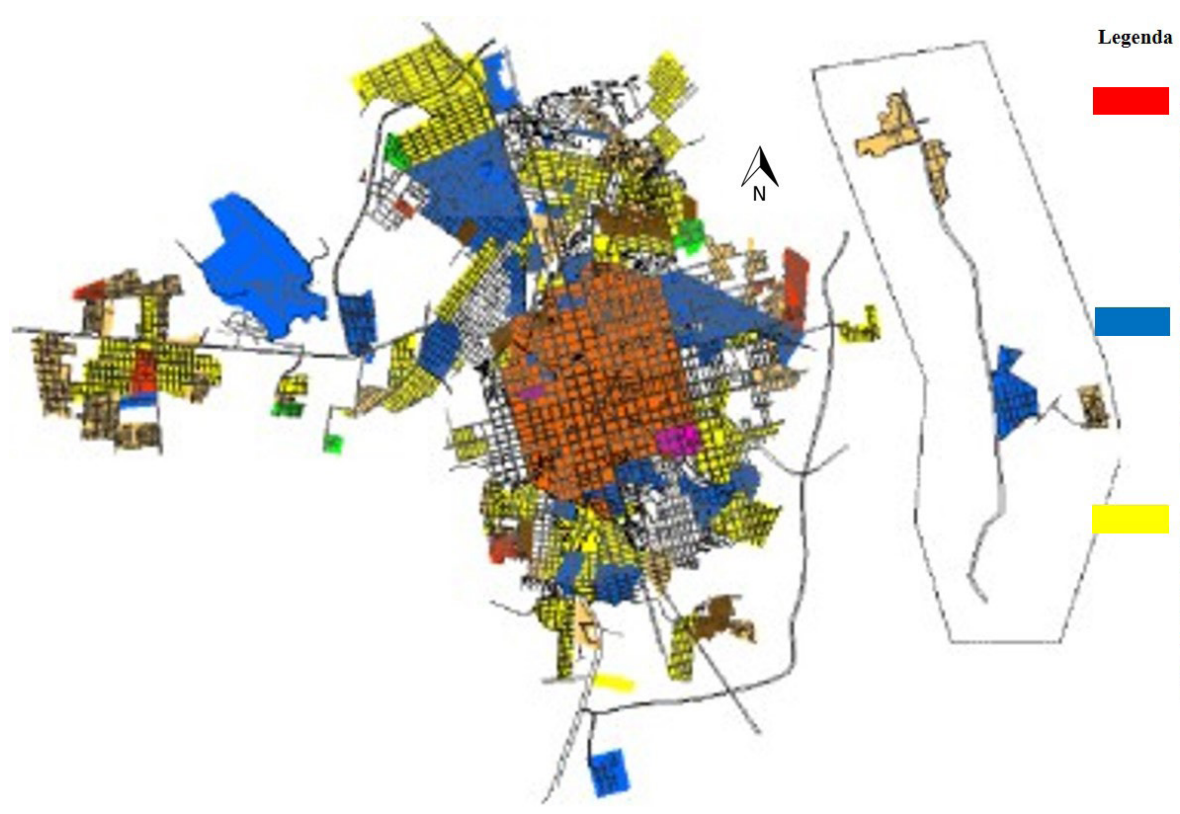

Adensamento na década de 1960 desenho do traçado concebido de forma extremamente organizacional com a implantação de vias retas e alinhadas que se cruzam em ângulos retos (ortogonais), constituindo, assim, o formato de um tabuleiro xadrez.

Adensamento na década de 1970 den maior parte reafirma um tabuleiro de xadrez, mas não mais contíguo a urbanização existente, formando vazios urbanos e espraiando a urbanização.

Adensamento em 2001 - o desenho do traçado se complexifica diversifica, a fim de atender diferentes demandas de urbanização. caixas viárias são reduzidos e a redução das conexões segrega bairros em áreas periféricas.
Figura 4 - núcleo urbano de Chapecó. Fonte: adaptado de Villela (2007,

p. 171).

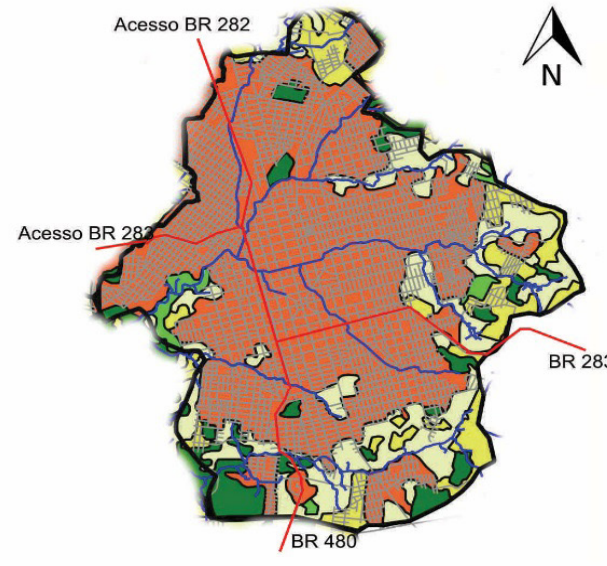

FLORESTAS EM ESTAGIO MEDIO OU AVANCADO E/OU PRIMARIAS
Legenda

$\square$ UNIDADE DE PAISAGEM

- CURSOS_D'ÁGUA_MUNICIPIO

VIAS

$\square$ AGRICULTURA

AREA URBANIZADA E/OU CONSTRUIDA

$\square$ CORPOS D'AGUA

$\square$ PASTAGENS E CAMPOS NATURAIS

$\square$ REFLORESTAMENTOS

$\square$ SOLO EXPOSTO

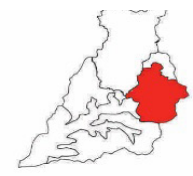

0
Fonte: Base cartográfica do estado de Santa Catarina; levantamento do uso do solo Epagri/Ciram.

Elaboração e edição: Daiane Regina Valentini e Ana Laura Villela, 2018. 


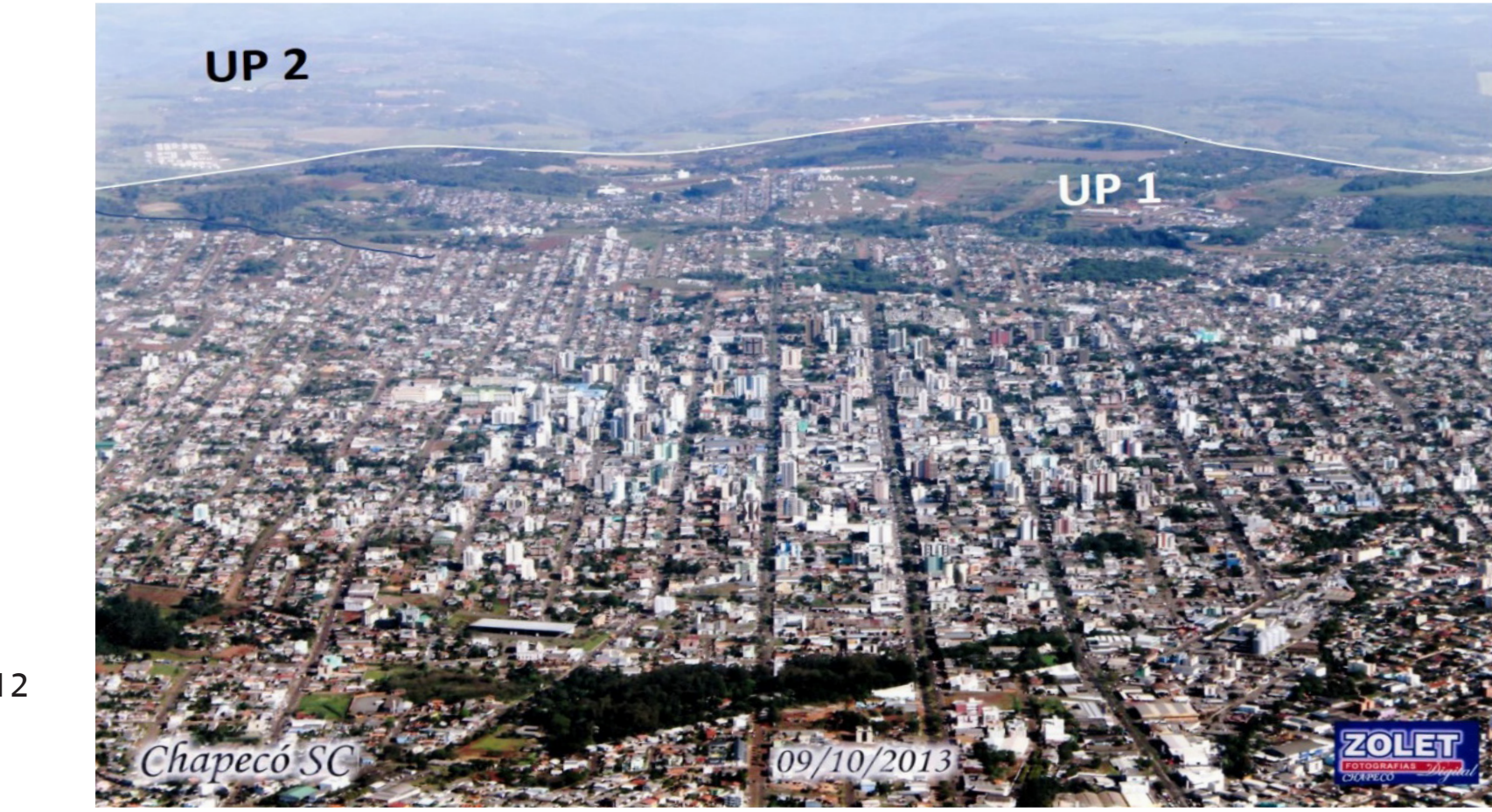

Figura 6 - Área urbana consolidada que conforma a UP1 e área de uso predominantemente agrícola da UP2.

Fonte: Foto de Victorino Zolet (outubro, 2013), editada por Alexandre M. Matiello, 2016

$3 \%$ a $20 \%$ com manchas planas de $0 \%$ a 3\%; resquícios de vegetação de floresta em estágio médio ou avançado nas bordas; e restrita capilaridade hídrica, mas bem distribuída pela unidade. Abarca a maior parte da área urbanizada e apresenta os registros de todos os processos de consolidação e expansão do núcleo urbano (tanto pela inserção da planta das agroindústrias, que se conformaram como vetor de expansão urbana, bem como pela atuação estatal, através de programas governamentais de infraestrutura urbana ${ }^{3}$ ); e das atividades econômicas, de serviços (principalmente de educação e saúde) e de produção. Nes-

3 Foi o caso do Programa Comunidade Urbana de Recuperação Acelerada (Cura), de meados dos anos 1970, que privilegiou e valorizou algumas áreas ao intervir, principalmente, com pavimentação de ruas e passeios (CHAPECÓ, 1979). sa unidade se conectam os quatro acessos ao município: BR 283 (sentido leste-oeste), BR 480 (ao sul) e acesso a BR 282 (ao norte - conexão com o litoral a leste e a fronteira internacional com a Argentina a oeste).

A UP 2 (Figura 7) se caracteriza pela ocupação residencial, agrícola e recreacional esparsa e industrial, por ser a conexão sul do município (BR 480) e por apresentar topografia favorável à urbanização (Figura 6). Representa $21 \%$ da área total em estudo, e se caracteriza pelo equilíbrio entre pastagens e campos naturais, agricultura, florestas em estágio médio ou avançado e pontos de reflorestamento e área urbanizada e/ou construída. Tem relevo de solos suavemente ondulado e ondulado, e declividade predominante de $3 \%$ a $8 \%$ e áreas significativas de $8 \%$ a $20 \%$, poucas 
Figura 7 - Unidade de paisagem 2. Fonte: Base cartográfica do estado de Santa Catarina; levantame de Santa Catarina; levanCiram. Elaboração e edição: Daiane Regina Valentini e Ana Laura Villela, 2018.
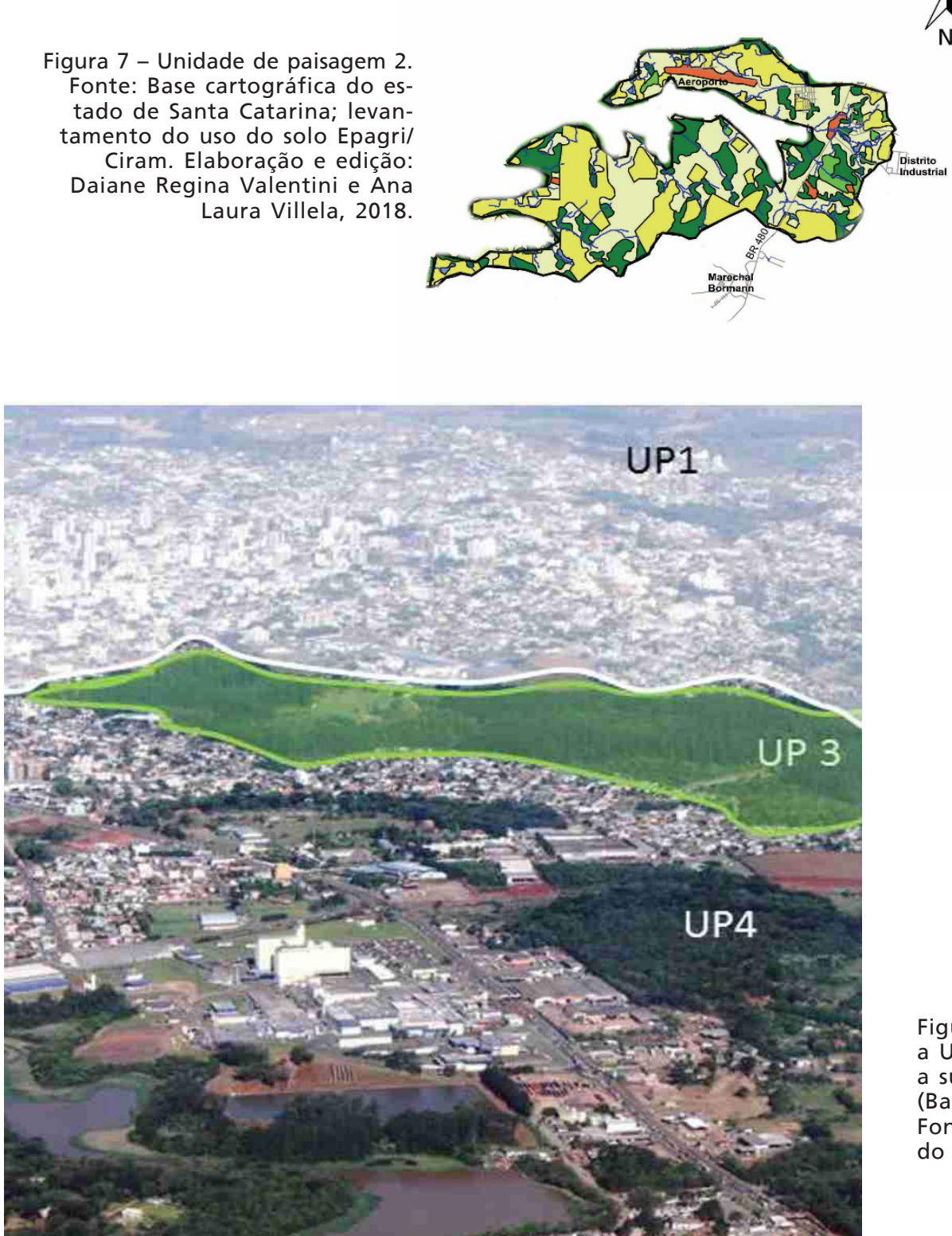

Figura 8 - Área urbana consolidada que conforma a UP1, o fundo de Vale do Rio Taquaruçú (UP3) e a subcentralidade com área urbanizada consolidada (Bairro Efapi - UP4).

Fonte: foto de Victorino Zolet (outubro, 2013), editado por Alexandre M. Matiello, 2016. 
áreas de vegetação de floresta em estágio médio ou avançado distribuídas pela unidade, resquício de reflorestamento e capilaridade hídrica mais presente e bem distribuída pela unidade. Dá acesso pelo sul do município a estudantes, trabalhadores e cargas, sendo eixo de conexão com o Rio Grande do Sul. Caracteriza-se pela atividade industrial ao longo da BR 480, com núcleo habitacional isolado (Marechal Bormann) e sedes de clubes. Sofre grande impacto por causa desta acessibilidade/mobilidade e pela pressão de urbanização por ela acarretada. Também funciona como conexão local e regional ao aeroporto.

A UP 3 (Figura 9) se conforma pelo vale do Rio Taquaruçú, pela vegetação remanescente, e acentuada declividade - sem urbanização intensiva e com características voltadas à preservação ambiental. (Figura 8, 10 e 14). Representa 20\% da área total em estudo. Destaca-se pela grande área de florestas em estágio médio ou avançado, com boa representatividade de pastagens e campos naturais e resquícios de agricultura e uso para reflorestamento. O relevo é fortemente ondulado, com grandes declividades - predomínio de $20 \%$ a $45 \%$, constituindo o Vale do Rio Taquaruçú. Há expressivo espaço livre vegetado esparsamente antropizado, constituindo áreas de preservação e pequenas propriedades de produção agrícola e ambiental não protegidas pela legislação local. Historicamente a ação antrópica foi pequena, situação que vem se alterando com a implantação do contorno viário, que gera pressão para ocupação ao longo desse eixo.

A UP 4 (Figura 11) se mostrou como uma subcentralidade com área urbanizada consolidada (Bairro Efapi) e bordas em expansão, abrigando importantes vetores de crescimento, tais como
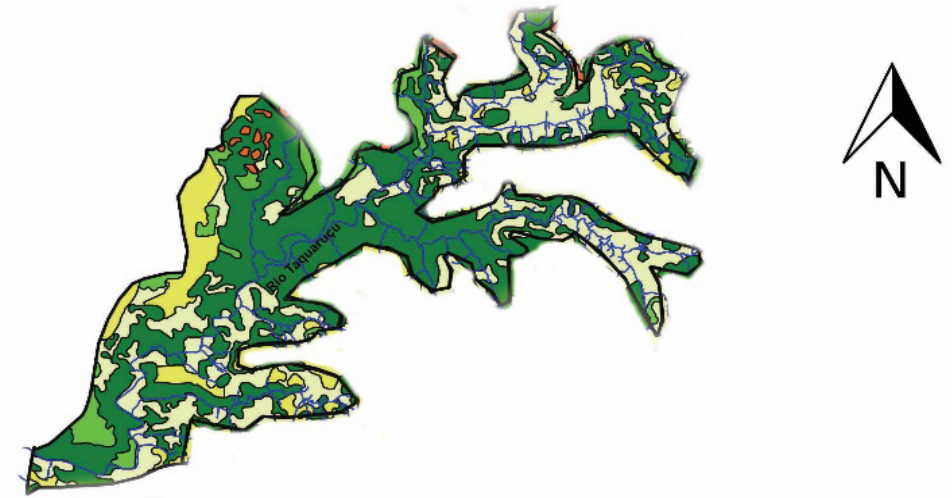

Legenda
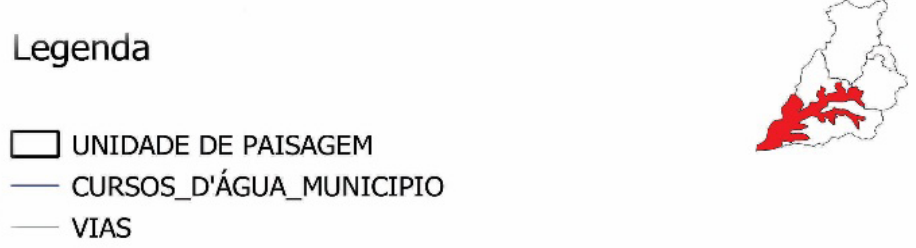

usodosolocompartimento Artigo

$\square$ AGRICULTURA

AREA URBANIZADA E/OU CONSTRUIDA

CORPOS D'AGUA

FLORESTAS EM ESTAGIO MEDIO OU AVANCADO E/OU PRIMARIAS

PASTAGENS E CAMPOS NATURAIS

REFLORESTAMENTOS

SOLO EXPOSTO

$$
0
$$

5 $10 \mathrm{~km}$

Figura 9 - Unidade de paisagem 3.

Fonte: Base cartográfica do estado de Santa Catarina; levantamento do uso do solo Epagri/Ciram. Elaboração e edição: Daiane Regina Valentini e Ana Laura Villela, 2018. 


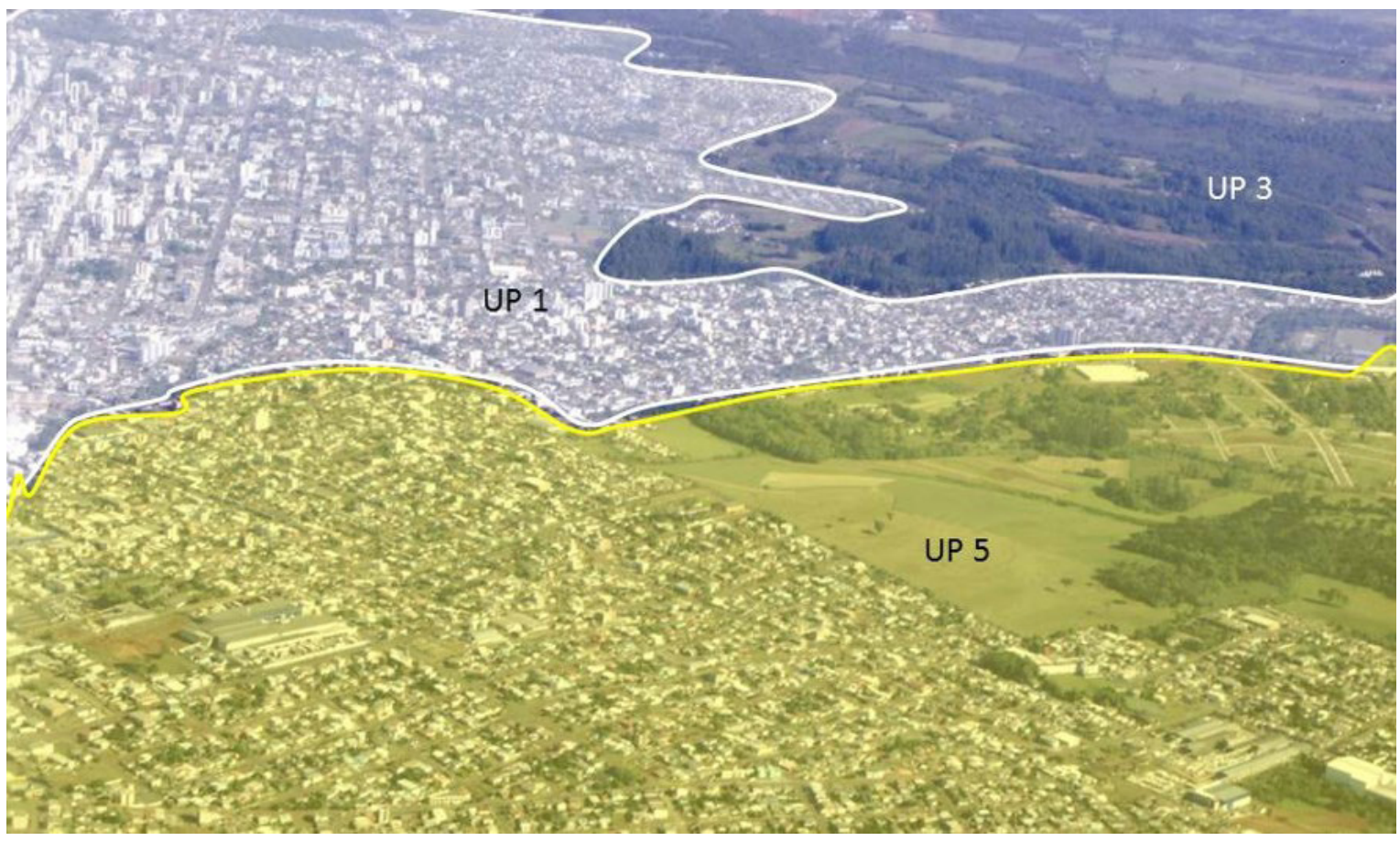

Figura 10 - Unidade de paisagem 5: área mais consolidada e onde há grande vazio urbano em processo de urbanização.

Fonte: foto de Victorino Zolet (outubro, 2013), editado por Alexandre M. Matiello, 2016.

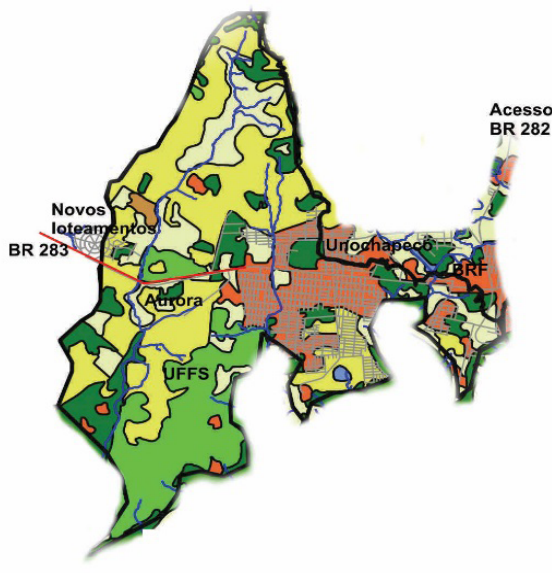
N
Legenda
$\square$ UNIDADE DE PAISAGEM
— CURSOS_D'ÁGUA_MUNICIPIO
VIAS

\section{$\square$ AGRICULTURA}

AREA URBANIZADA E/OU CONSTRUIDA

CORPOS D'AGUA

FLORESTAS EM ESTAGIO MEDIO OU AVANCADO E/OU PRIMARIAS

$\square$ PASTAGENS E CAMPOS NATURAIS

$\square$ REFLORESTAMENTOS

$\square$ SOLO EXPOSTO

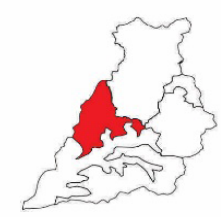

0

5

$10 \mathrm{~km}$

Figura 11 - Unidade de paisagem 4 Fonte: Base cartográfica do estado de Santa Catarina; levantamento do uso do solo Epagri/Ciram.

Elaboração e edição: Daiane Regina Valentini e Ana Laura Villela, 2018. 
as universidades (Universidade Federal da Fronteira Sul (UFFS) e Universidade Comunitária da Região de Chapecó (Unochapecó)), agroindústrias (Aurora e BRF) e novos loteamentos (Figura 8). Representa $12 \%$ da área total em estudo, destacando-se a grande área de agricultura e o equilíbrio entre reflorestamento, pastagens e campos naturais, florestas em estágio médio ou avançado e área urbanizada. Tem relevo de solos ondulados, com declividade predominante de $3 \%$ a $20 \%$ com manchas planas de até $3 \%$ e restrita capilaridade hídrica, mas bem distribuída pela unidade. Importante área urbanizada que se consolida principalmente quando da expansão da malha (sentido leste-oeste) e da instalação das agroindústrias. Funciona como acesso oeste ao município pela BR 283 - para estudantes, trabalhadores e pelos que utilizam serviços de saúde - e de conexão com a fronteira internacional (Argentina). Está associado a importante mancha urbana (Bairro Efapi), que é polo educacional e comercial, e área de expansão urbana, e por isso sofre grande pressão para ocupação.

A UP 5 (Figura 12) é a área da bacia de captação de água potável do município, que possui zoneamento específico com lotes mínimos de $600 \mathrm{~m}^{2}$ com intuito de reduzir o impacto quanto à permeabilidade do solo (Figuras 10 e 14). Está sendo ocupada com urbanizações mais densas e consolidada com resquícios de áreas de preservação ambiental. Representa $28 \%$ da área total em estudo, onde se destacam áreas de pastagem, campos naturais e agricultura, e o equilíbrio entre florestas em estágio médio ou avançado, área urbanizada e reflorestamento. A UP possui relevo de solos ondulados, declividade predominante de $3 \%$ a $20 \%$, com manchas planas de até $3 \%$ e grande capilaridade hídrica bem distribuída pela unidade. Serve como acesso norte ao município para estudantes, trabalhadores, cargas e procura pelos serviços de saúde pela BR 282. É eixo de conexão com o estado do Paraná a norte (escoamento e entrada da produção), com o litoral leste do estado de Santa Catarina e com a fronteira internacional (Argentina) a oeste. É caracterizada pela atividade atacadista e de logística e núcleos habitacionais isolados. Constitui área ambiental que anteriormente estava protegida pela legislação, mas que com o Plano Diretor dos anos 2000 (CHAPECÓ, 2004; 2007; 2014) e suas alterações, sofre grande pressão para ocupação e urbanização.

A UP 6 (Figura 13) se mostrou uma área em expansão da urbanização muito em função do futuro vetor de desenvolvimento (contorno leste) e por sua topografia favorável (Figura 14). Representa $3 \%$ da área total em estudo, e se destaca pela existência de áreas de agricultura, pastagens e campos naturais e a representatividade de florestas em estágio médio ou avançado e resquícios de reflorestamento e área urbanizada. Tem relevo de solos ondulados, declividade predominante de $8 \%$ a $20 \%$ e áreas significativas de $3 \%$ a $8 \%$ com manchas planas de $0 \%$ a $3 \%$ e capilaridade hídrica mais presente e bem distribuída pela unidade. Área esparsamente antropizada, que possui boas características para expansão urbana. Não se estabelece como eixo de conexão nem local e nem regional e contempla atividades de produção primária. Na atualidade está recebendo pressão para ocupação e urbanização.

O método possibilitou o estudo comparativo, a problematização e a avaliação das UPs enquanto ordenadoras do território e qualificadoras da paisagem, bem como auxiliaram na reflexão sobre o macrozoneamento incidente na Sub-Bacia do Lajeado São José. De forma sintetizada tem-se na Tabela 1: 


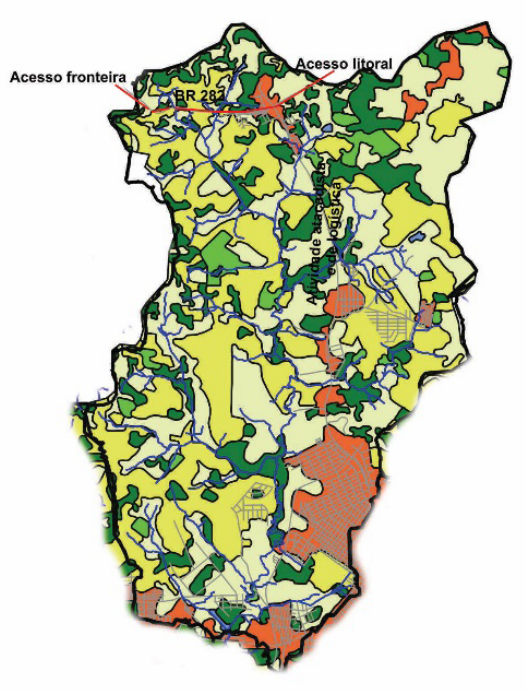

Legenda

UNIDADE DE PAISAGEM

CURSOS_D'ÁGUA_MUNICIPIO

- VIAS

\section{AGRICULTURA}

AREA URBANIZADA E/OU CONSTRUIDA

CORPOS D'AGUA

FLORESTAS EM ESTAGIO MEDIO OU AVANCADO E/OU PRIMARIAS

PASTAGENS E CAMPOS NATURAIS

REFLORESTAMENTOS

SOLO EXPOSTO

$10 \mathrm{~km}$

\section{Legenda}

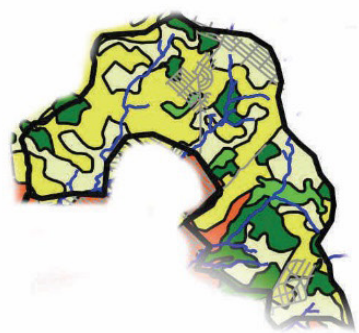

UNIDADE DE PAISAGEM

CURSOS_D'ÁGUA_MUNICIPIO

- VIAS

\section{AGRICULTURA}

AREA URBANIZADA E/OU CONSTRUIDA

CORPOS D'AGUA

FLORESTAS EM ESTAGIO MEDIO OU AVANCADO E/OU PRIMARIAS

PASTAGENS E CAMPOS NATURAIS

REFLORESTAMENTOS

SOLO EXPOSTO
Figura 12 - Unidade de paisagem 5. Fonte: Base cartográfica do estado de Santa Catarina; levantamento do uso do solo Epagri/Ciram.

Elaboração e edição: Daiane Regina Valentini e Ana Laura Villela, 2018.

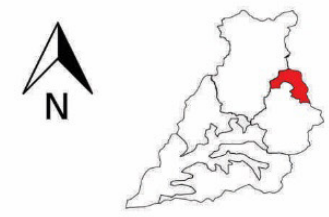

Figura 13 - Unidade de paisagem 6. Fonte: Base cartográfica do estado de Santa Catarina; levantamento do uso do solo Epagri/Ciram.

Elaboração e edição: Daiane Regina Valentini e Ana Laura Villela, 2018.

0

5

$10 \mathrm{~km}$ 


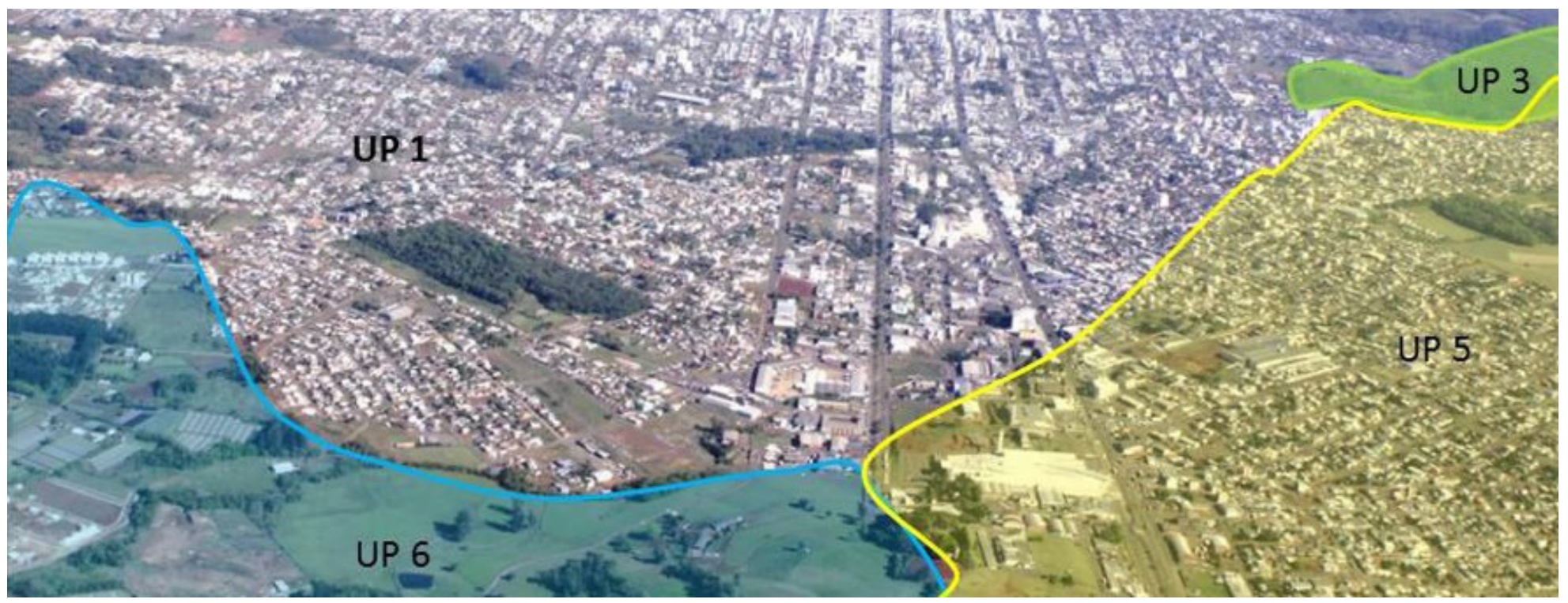

Figura 14 - Unidade de paisagem 6: área que conserva uso agrícola, mas vem sofrendo urbanização mais recente. Fonte: foto de Victorino Zolet (Outubro, 2013), editado por Alexandre M. Matiello, 2016.

Tabela 1 - Caracterização das unidades de paisagem da Sub-bacia do Lajeado São José

\begin{tabular}{c|l}
\hline UP 1 & Destaca-se pela predominância da área urbanizada e pela conexão das quatro portas de entrada ao município; \\
\hline UP 2 & $\begin{array}{l}\text { Destaca-se por ser a porta sul de entrada ao município (conexão ao aeroporto e ao Rio Grande do Sul) - com forte pre- } \\
\text { sença de atividade industrial e sedes de clubes; }\end{array}$ \\
\hline UP 3 & $\begin{array}{l}\text { Destaca-se pela grande área verde esparsamente antropizada - fundo de vale do Rio Taquaruçú com área ambiental } \\
\text { não protegida pela legislação local e pequenas propriedades de produção; }\end{array}$ \\
\hline UP 4 & $\begin{array}{l}\text { Destaca-se por ser a porta oeste do município e abrigar importante área urbanizada (Bairro Efapi) e conexão com a } \\
\text { fronteira internacional (Argentina); }\end{array}$ \\
\hline UP 5 & $\begin{array}{l}\text { Contempla grande parte da bacia de captação de água do município e representa a porta norte de acesso ao município } \\
\text { - ao estado do Paraná, ao litoral do estado de SC e à fronteira internacional (Argentina), com forte presença da ativi- } \\
\text { dade atacadista ao longo do acesso; }\end{array}$ \\
\hline UP 6 & $\begin{array}{l}\text { É uma área esparsamente antropizada, que possui boas características para expansão urbana - não se estabelece como } \\
\text { eixo de conexão nem local e nem regional e contempla atividades de produção primária. }\end{array}$ \\
\hline
\end{tabular}


De modo geral, os dados levam a entender que a matriz agroindustrial e o recente processo de consolidação da urbanização desse município (após 1980) têm interferido no entendimento atual da complexidade que se apresenta nesse território, visto o delineamento do macrozoneamento do município de Chapecó com apenas duas grandes caracterizações: urbano e rural (Figura 15).

O método de avaliação da paisagem, considerando os processos de construção social e de transformação da Sub-Bacia do Lajeado São José, mostra que, para essa escala de análise do território, o desenho da paisagem e a estrutura morfológica são os parâmetros mais importantes enquanto identificadores das UPs. Os conflitos socioambientais e os padrões de ocupação se apresentaram como um aprofundamento desta caracterização. As unidades de paisagem, desta forma, descrevem e permitem interpretar a paisagem que se apresenta de configuração homogênea, a partir da identificação dos tipos morfológicos incidentes na escala da sub-bacia e que se relacionam diretamente à compreensão dos atributos qualificadores dessa paisagem e no planejamento desse território, principalmente no sentido de suas vivências e significados sociais.

Especificamente quanto ao planejamento do território, percebese a importância de compreender as unidades de paisagem. Os estudos, as análises e as reflexões realizadas, quando confrontadas com o macrozoneamento do município de Chapecó (2014), apontam para a necessidade do refinamento da política pública para esse território, a qual deve assumir delineamentos mais pautados no processo de urbanização, produção, abastecimento, vivências e significados sociais.

Nesse sentido, a partir da análise da Sub-Bacia do Lajeado São José, comprova-se a necessidade do redesenho do macrozoneamento do município de Chapecó de duas para pelo menos quatro macrozonas (Figura 16). A primeira explicitando os processos de consolidação da mancha urbana que se expressam fortemente nas UPs 1, 4, parte da 5 (precisa-se considerar que parte da bacia de captação possui ocupação não recente) e maior que a UP 6; a segunda de conservação/preservação - UPs 3 (Vale do Rio Taquaruçú) e parte da UP 5 (parte da bacia de captação de água); a terceira de áreas periurbanas caracterizadas pela multifuncionalidade (produção - industrial e primária - e de serviços, lazer, moradia) e ocupação urbana fragmentada a partir de processos de expansão (UP 2 e UP 4); e a quarta, a macrozona rural, caracterizada por atividades de produção primária e recreacional (área municipal fora da sub-bacia - a ser estudada).

\section{Conclusão e desdobramentos}

Este estudo dá um passo adicional na identificação dos fatores para interpretação da dinâmica espacial da paisagem de Chapecó ao mostrar como as UPs avançam como método de análise e se colocam como importante ferramenta de descrição e interpretação da paisagem a partir do estudo e compreensão das heterogeneidades/homogeneidades do território e, consequentemente, como elemento fundamental a ser considerado nas decisões de planejamento. Esse contexto resulta da interação dinâmica de seus componentes, que na visão multiescalar explicita a estrutura morfológica como elemento de análise da escala da cidade/fragmentos/sub-bacia. Nesse sentido, dá luz a processos mais qualitativos que se constroem a partir da interligação dos fatores - como os que caracterizam as cidades médias/não metropolitanas a partir da década de 1980 -, e coloca como fundamental a compreensão das relações espaciais entre os elementos da paisagem.

Contribuindo nesse ponto, avalia-se neste artigo os tipos morfológicos que apresentam atributos de qualificação da paisagem da Sub-Bacia do Lajeado São José da cidade de Chapecó-SC, a partir da identificação e caracterização dos agentes e processos físico-ambientais atuantes na área e que afetam diretamente o processo de construção social dessa paisagem. Com isso, reforçase a importância e amplitude deste estudo para a compreensão das cidades ao demonstrar como o pensamento ecológico avança e embasa o necessário aprimoramento das políticas públicas neste caso ao redesenhar os macrozoneamentos e suas interfaces com a dinâmica espacial da paisagem.

Por fim, entende-se estar colocada uma nova agenda de trabalho e pesquisa para aprofundar o estudo de cada unidade 


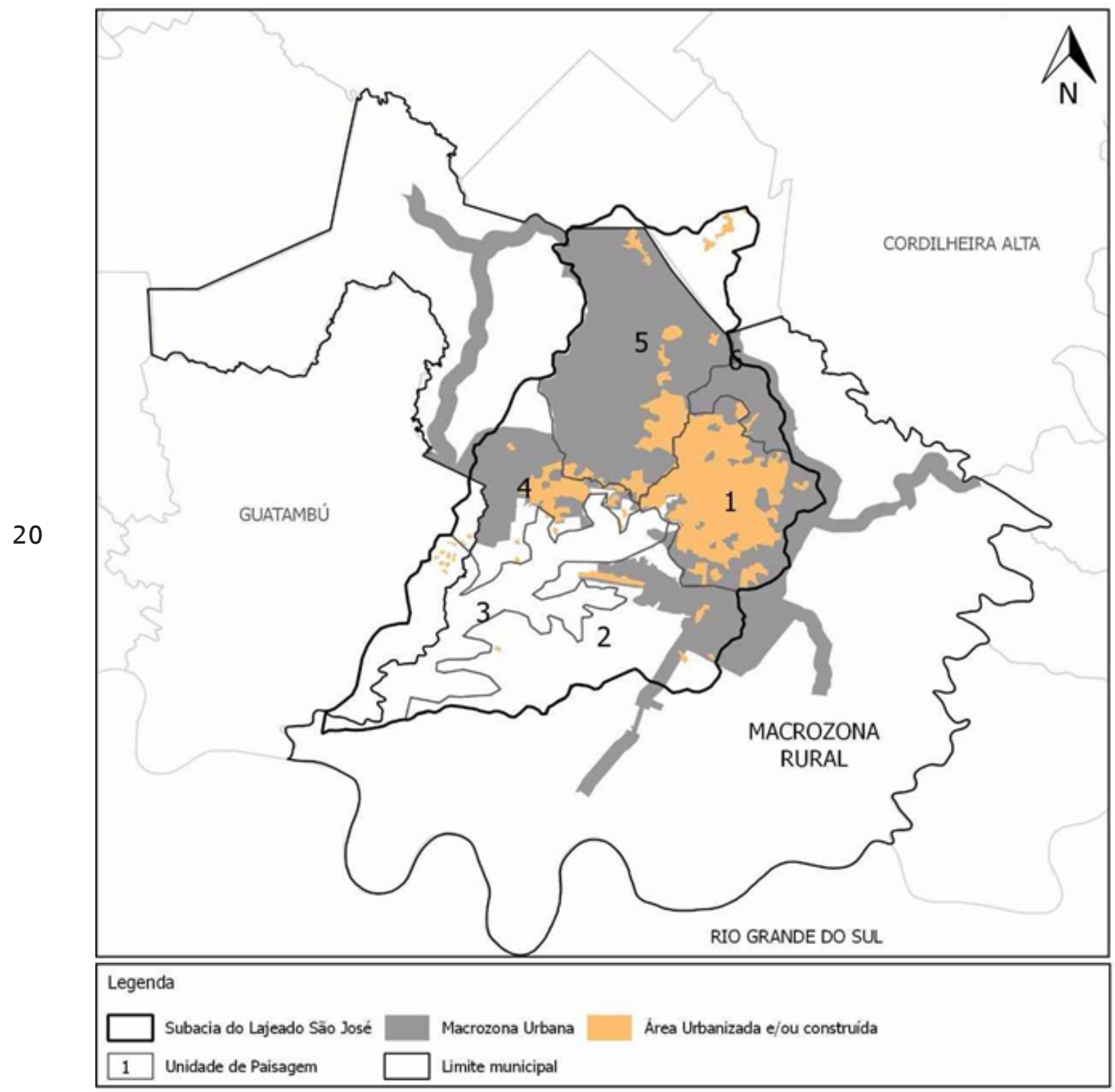

Figura 15 - Confronto do

macrozoneamento do município de

Chapecó (2014) e as unidades de paisagem identificadas.

Fonte: Base cartográfica do estado de

Santa Catarina. Elaboração e edição:

Daiane Regina Valentini, 2017. 


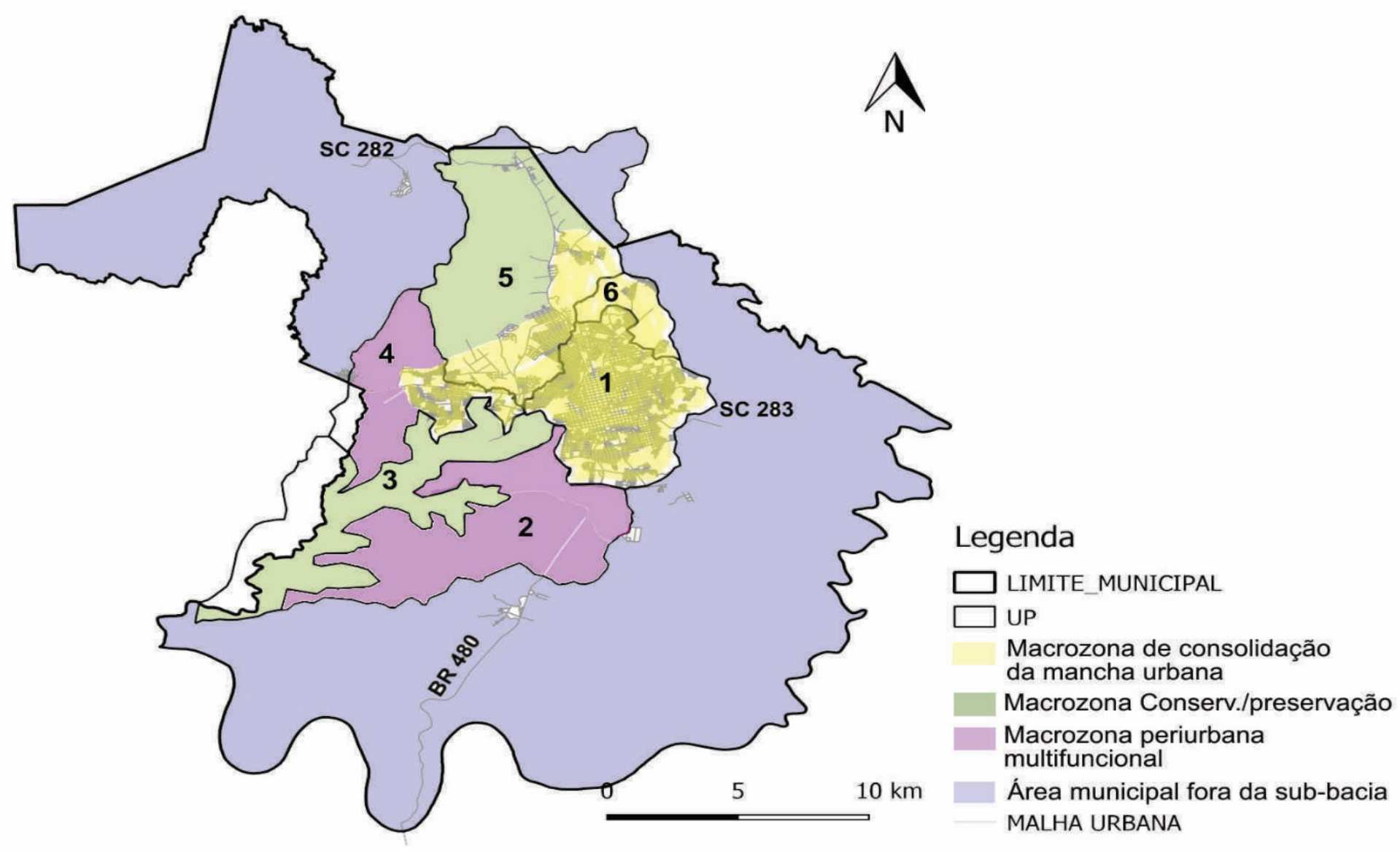

Figura 16 - Redesenho do macrozoneamento do município de Chapecó (2014) a partir das unidades de paisagem identificadas. Fonte: Base cartográfica do estado de Santa Catarina; sistema viário de Chapecó. Elaboração e edição: Ana Laura Vianna Villela, 2018. 
de paisagem aqui caracterizada no que tange à compreensão e contextualização dos elementos que compõem o sistema de espaços livres, para sua efetiva sistematização em prol da qualidade de vida.

\section{Bibliographical References}

AB'SÁBER, Aziz. Os domínios de natureza no Brasil: potencialidades paisagísticas. São Paulo: Ateliê Editorial, 2003

AGÊNCIA NACIONAL DE ÁGUAS. Atlas Brasil, 2010. Disponível em: http://atlas.ana.gov.br/ Atlas/forms/Home.aspx. Acesso em: 28 fev. 2017.

ARENDT, Hannah. A condição humana. 2. ed. Rio de Janeiro: Forense Universitária, 1983.

BERTRAND, Georges. Paisagem e geografia física global: o espaço metodológico. Tradução de Olga Cruz. RA'E GA, Curitiba, n. 8, p. 141-152, 2004.

BRASIL. Ministério do Meio Ambiente. Caderno da região hidrográfica do Uruguai. Brasília, DF: Ministério do Meio Ambiente, 2006. Disponível em: http://www.mma.gov.br/estruturas/161/_publicacao/161_publicacao03032011023025.pdf. Acesso em: 28 fev. 2017.

BRASIL. Ministério do Desenvolvimento Agrário. Plano territorial de desenvolvimento rura sustentável: oeste catarinense. Brasília, DF: Ministério do Desenvolvimento Agrário, 2010.

CHAPECÓ Lei no 68 , de 31 de dezembro de 1974. Aprova o plano de desenvolvimento urbano de Chapecó, conforme especifica. Diário Oficial de Chapecó, Chapecó, 31 dez. 1974.

CHAPECÓ. Programa Cura: Chapecó: plano de complementação urbana. Chapecó [s. n.]: 1979.

CHAPECÓ. Lei Complementar n 4, de 31 de maio de 1990. Estabelece normas e diretrizes básicas referentes ao planejamento, ordenamento territorial, controle, uso, parcelamento, ocupação do solo urbano e dá outras providências. Diário Oficial de Chapecó, Chapecó, 31 maio 1990.

CHAPECÓ Lei Complementar $n^{\circ} 202$ de 6 de janeiro de 2004. Institui o Plano Diretor de Desenvolvimento Territorial de Chapecó - PDDTC. Diário Oficial de Chapecó, Chapecó, 6 jan. 2004.

CHAPECÓ. Lei complementar $n^{\circ} 317$, de 17 de outubro de 2007. Modifica a Lei Complementar $n^{\circ} 202$, de 6 de janeiro de 2004, que institui o Plano Diretor de Desenvolvimento Territoria de Chapecó - PDDTC. Diário Oficial de Chapecó, Chapecó, 17 out. 2007.

CHAPECÓ. Lei Complementar n541, de 26 de novembro de 2014. Aprova o Plano Diretor de Chapecó - PDC. Diário Oficial de Chapecó, Chapecó, 27 nov. 2014.

CORRÊA, Roberto Lobato. Estudos sobre a rede urbana. Rio de Janeiro: Bertrand Brasil, 2006 CONSELHO DA EUROPA. Convenção Europeia de Paisagem. Florença, 2000. Disponível em https://rm.coe.int/16802f3fb7. Acesso em: 28 fev. 2017.

FORMAN, Richard T. T.; GODRON, Michel. Landscape ecology. New York: Wiley, 1986.

FORMAN, Richard T. T. Land mosaics: the ecology of landscapes and regions. Cambridge: Cambridge University Press, 1995.
FORMAN, Richard T. T. Urban regions: ecology and planning beyond the city. Cambridge: Cambridge University Press, 2008

HASS, Monica; ALDANA, Myriam; BADALOTTI, Rosana Maria. A possibilidade de um pacto social à luz dos princípios do Estatuto da Cidade: o plano diretor de Chapecó (SC). In: HASS, Monica; ALDANA, Myriam; BADALOTTI, Rosana Maria (org.). Os planos diretores e os limites de uma gestão urbana democrática: as experiências de Chapecó, Xanxerê e Concórdia (SC). Chapecó: Argos, 2010. p. 59-120.

IBGE. Panorama de Chapecó-SC. Brasília, DF: IBGE, 2017. Disponível em: https://cidades.ibge. gov.br/brasil/sc/chapeco/pesquisa/1/21682. Acesso em: 17 jul. 2019.

LEITE, Maria Angela Faggin Pereira. A paisagem, a natureza e a natureza das atitudes do homem. Paisagem e Ambiente, São Paulo, n. 4, p. 45-55, 1992.

MACEDO, Silvio Soares. Quadro do paisagismo no Brasil: 1783-2000. São Paulo: Quapá, São Paulo, 1999.

MATIELLO, Alexandre Mauricio; VILLELA, Ana Laura Vianna; FUJITA, Camila; OTSUSCHI, Cristina; ALBA, Rosa Salete. Chapecó/SC: o agronegócio, o setor terciário em expansão e a crescente desigualdade socioespacial. In: SPOSITO, Maria Encarnação Beltrão; MAIA, Doralice Sátyro (org.). Agentes econômicos e reestruturação urbana e regional: Dourados e Chapecó. São Paulo: Cultura Acadêmica, 2016. p. 171-319.

METZGER, Jean Paul. O que é ecologia de paisagens? Biota Neotropica, São Paulo, v. 1, n. 1, p. 1-9, 2001.

MONTEIRO, Ricardo Rodrigues. Habitação e integração urbana: um estudo de caso em programas habitacionais no município de Chapecó-SC. 2006. $182 \mathrm{f}$. Dissertação (Mestrado em Engenharia Civil) - Universidade Federal de Santa Catarina, Florianópolis, 2006.

RECHE, Daniella. Leis e planos urbanos na produção da cidade: o caso de Chapecó, SC. 2008 152 f. Dissertação (Mestrado em Urbanismo, História e Arquitetura da Cidade) - Universidade Federal de Santa Catarina, Florianópolis, 2008.

SANTOS, Milton. A urbanização brasileira. 2. ed. São Paulo: Hucitec, 1994.

SANTOS, Milton. Pensando o espaço do homem. 4. ed. São Paulo: Hucitec, 1997.

SANTOS, Milton. A natureza do espaço: técnica e tempo, razão e emoção. 4. ed. São Paulo: Hucitec, 2006.

SILVA, William Ribeiro da; SPOSITO, Maria Encarnação Beltrão. Perspectivas da urbanização: reestruturação urbana e das cidades. Rio de Janeiro: Consequência, 2017.

SCHLEE, Mônica Bahia; NUNES, Maria Julieta; REGO, Andrea Queiroz; RHEINGANTZ, Paulo; DIAS, Maria Ângela; TÂNGARI, Vera Regina. Sistema de espaços livres nas cidades brasileiras: um debate conceitual. Paisagem e Ambiente, São Paulo, n. 26, p. 225-247, 2009.

SOUZA, Marcelo José Lopes de. O território: sobre espaço e poder, autonomia e desenvolvimento. In CASTRO, Iná Elias de; GOMES, Paulo César da Costa; CORRÊA, Roberto Lobato (org.). Geografia: conceitos e temas. Rio de Janeiro: Bertrand Brasil, 1995. p. 77-116.

SOUZA, Marcelo José Lopes de. Os conceitos fundamentais da pesquisa sócio-espacial. 2. ed. Rio de Janeiro: Bertrand Brasil. 2015.

SPOSITO, Maria Encarnação Beltrão. Cidades médias: espaços em transição. São Paulo: Expressão Popular, 2007. 
TÂNGARI, Vera Regina. Um outro lado do Rio. 1999. Tese (Doutorado em Arquitetura e Urbanismo) - Faculdade de Arquitetura e Urbanismo, Universidade de São Paulo, São Paulo, 1999.

TÂNGARI, Vera Regina; REGO, Andréa Queiroz; DIAS, Maria Ângela; AFONSO, Paulo; RHEINGANTZ, Giselle; MONTEZUMA, Rita; SOUZA, Maria Julieta; SCHLEE, Mônica Bahia; CARDEMAN, Rogério; WOPEREIS, Brunna; CAPILLE, Cauê Costa; PARAHYBA, Natalia; AMORIM Marcos; NEVES, Elaine; SILVA, Maria Alice; VIEIRA, Guilherme; GORINI, Inês; ANDRADE, Rubens de: MELCÍADES, Alexandre Luiz B · GOMES, Domitila. Morfologia urbana: suporte geobio-físico 0 sistema de expasos livres do Rio de Janiro - MJ. In: CAMPOS, Ana: suporte geoDio-fisico QUEIROGA, EuCDO (org.). Quadro dos Livres nas cidades brasileiras. São Paulo: Quapá-SEL, 2012. p. 195-238.

TÂNGARI, Vera Regina. Espaços livres e a forma urbana: identificação dos tipos-morfológicos que qualificam a paisagem urbana. In: ENCONTRO DA ASSOCIAC̃̃O NACIONAL DE PESOUISA E PÓS-GRADUAÇÃO EM ARQUITETURA E URBANISMO, 3., 2014, São Paulo. Anais [...]. São Paulo: 2014. p. 1-19.

VILLELA, Ana Laura Vianna. Colonização, cultura e território: o caso de Chapecó/SC. Cadernos do CEOM, Chapecó, v. 27, n. 27, p. 159-185, 2007.

VILLELA, Ana Laura Vianna; ALBA, Rosa Salete; MAIA, Claudio; ARRUDA, Laiz. Região metropolitana de Chapecó: dinâmicas regionais e suas territorialidades. In: ENCONTRO NACIONAL DE TECNOLOGIA URBANA, 2., 2015, Passo Fundo. Anais [...]. Passo Fundo: Editora da Universidade de Passo Fundo, 2015. p. 112-123.

WELTER, Liane. O espaço geográfico do oeste catarinense e sua cartografia ambiental. 2006. 91 f. Dissertação (Mestrado em Geografia Humana) - Faculdade de Filosofia, Letras e Ciências Humanas, Universidade de São Paulo, São Paulo, 2006.

WU, Jianguo. Landscape ecology. In: LEEMANS, Rik (ed.). Ecological systems: selected entries from the Encyclopedia of Sustainability, Science and Technology. New York: Springer, 2012 p. $179-200$.

\section{Ana Laura Vianna Villela}

Universidade Comunitária da Região de Chapecó (Unochapecó), Área de Ciências Exatas e Ambientais (Acea), Curso de Arquitetura e Urbanismo. Rua Santo Amaro da Imperatriz, 107D - Seminário - Chapecó, SC, Brasil, CEP 89813-130

CV: http://lattes.cnpq.br/1723289699887548

Orcid: http://orcid.org/0000-0003-3782-484X

avillela@unochapeco.edu.br
Daiane Regina Valentin

Universidade Federal da Fronteira Sul (UFFS), Campus Erechim, Curso de Arquitetura e Urbanismo.

ERS 135 Km 72, 200, Caixa Postal 764, Erechim, RS, Brasil, CEP 99700-970

CV: http://lattes.cnpq.br/4358020039164803

Orcid: http://orcid.org/0000-0002-3137-8386

daiane.valentini@uffs.edu.br

Alexandre Mauricio Matiello

Universidade Federal da Fronteira Sul (UFFS), Campus Chapecó, Licenciatura em Ciências Sociais.

Rodovia Balseiros do Rio Uruguai (SC 484) Km 2, bloco de professores, sala 103 - Fronteira Sul - Chapecó, SC, Brasil, CEP 89801-001

CV: http://lattes.cnpq.br/9493860855255203

Orcid: https://orcid.org/0000-0002-2210-3591

alexandre.matiello@uffs.edu.br

\section{Tomé Colett}

Universidade Federal Fronteira Sul (UFFS), Campus Chapecó.

Rua Pará, 645D - Maria Goretti - Chapecó, SC, Brasil, CEP 89801-400

CV: http://lattes.cnpq.br/9633056500514511

Orcid: https://orcid.org/0000-0002-0591-929X

tomecoletti@gmail.com

Vera Regina Tângari

Universidade Federal do Rio de Janeiro (UFRJ).

Avenida Pedro Calmon, 550, Prédio da Reitoria/FAU - Cidade Universitária - Rio de Janeiro, RJ, Brasil, CEP 21941-485

CV: http://lattes.cnpq.br/3263805844970643

Orcid: https://orcid.org/0000-0003-4608-7909

vtangari@gmail.com

\section{Nota do Editor:}

Submetido em: 11/05/2018

Aprovado em : 10/07/2019

Revisão: Tikinet 